\title{
Matching commercial thrips predating phytoseids with the highly diversified climatic conditions of different strawberry production systems.
}

\author{
R. Clymans ${ }^{1}$, H. Trekels 1 , M. Boonen' 1 , S. Craeye ${ }^{2}$, J. Hanssens' ${ }^{2}$, G. Smagghe ${ }^{3}$, M. Vervoort ${ }^{4}$, P. \\ Melis $^{4}$, D. Bylemans ${ }^{1,5}$ and T. Belien ${ }^{1 a}$
}

${ }^{1}$ Pcfruit vzw, Zoology department and Experimental garden for strawberry and ligneous small fruits, Sint-Truiden, Belgium; ${ }^{2}$ Inagro, Rumbeke-Beitem, Belgium; ${ }^{3}$ Ghent University, Dept. Crop Protection, Lab. Agrozoology, Ghent, Belgium; ${ }^{4}$ Research Centre Hoogstraten, Meerle, Belgium; ${ }^{5}$ KULeuven, Department of Biosystems, Leuven, Belgium

\begin{abstract}
Flower inhabiting thrips (Order: Thysanoptera) are a major threat to fruit quality in strawberry production around the world. As chemical control is often inefficient, alternative control measures are of broad and current interest. Their fast reproduction makes predatory mites highly suitable for thrips control in a crop with a relatively short cropping season like strawberry. However, climatic conditions of strawberry production can differ strongly depending on the production system (glasshouse, plastic tunnel, open field, ...) and the time span of cultivation (depending mostly on planting date and the type of cultivar: summer- or everbearing). As predatory mites typically display a temperature-dependent life history and the current commercially available thrips predating phytoseids vary in geographic origin, one can assume that under certain climatic conditions some species will be more applicable than others. The goal of this study is to determine which species are suitable for which climatic conditions. Therefore all (Belgian) production systems and time spans are categorized into three climate types, simulated in the laboratory. The population build-up of seven predatory mite species $(A$. degenerans, $A$. montdorensis, $A$. andersoni, A. limonicus, A. swirskii, N. cucumeris and $E$. gallicus) were assessed for each of these climatic conditions. Under the coldest condition (A), the in West-Europe indigenous $E$. gallicus was the only species with a significant population build up. When moderate conditions (B) were simulated E. gallicus, $N$. cucumeris and $A$. limonicus were most successful. The warmest regime (C) was most adequate for $E$. gallicus and $\boldsymbol{A}$. swirskii.
\end{abstract}

Keywords: biological control, Phytoseiidae, population growth, strawberry production, Thripinae

\section{INTRODUCTION}

Anthophilous thrips are a severe pest in strawberry, they cause damage to the fruit like bronzing, deformation and seedy appearance. For a fruit with very high quality standards like strawberry such imperfections have great economic consequences. Harmful species are Frankliniella occidentalis, invasive in Europe and predominant in greenhouses, and indigenous European species like Frankliniella intonsa, Thrips major, Thrips fuscipennis and Thrips tabaci. Reinfestation due to their high mobility and wide variety of hostplants, a quick

\footnotetext{
${ }^{\text {a } E-m a i l: ~ t i m . b e l i e n @ p c f r u i t . b e ~}$
} 
build-up of resistance due to their short life cycle and a low reachability due to thigmotactic behaviour make thrips hard to suppress with chemicals. Other incentives for searching alternative control measures are legal limitations in the use of chemical control and the rising demand for (extra-legal) residue minimisation on fruit.

Biological control by means of predatory mites is one of the options, their great advantage is their short life cycle which implies a population build-up fast enough to control thrips even in crops with a relatively short cropping season like strawberry. Naturally occurring Phytoseiidae on strawberry in Europe are Neoseiulus cucumeris, Typhlodromus pyri, Neoseiulus aurescens and (although not native to Europe) Neoseiulus californicus (Fitzgerald et al., 2007). Some of these are known to have a Type III lifestyle: Generalist predator (McMurtry et al., 2013). T. pyri is suggested by McMurtry et al. as subtype a: Generalist predators living on pubescent leaves and N. cucumeris as subtype e: Generalist predator from soil/litter habitats. $N$. cucumeris is currently the most advised phytoseid for thrips control. $N$. californicus is suggested by McMurtry et al. to have a Type II lifestyle: Selective predators of tetranychid mites, although it can also feed and reproduce on thrips $(F$. occidentalis) first instars (Van Baal et al., 2007).

Although there are potentially natural predatory mite species present, their augmentation in strawberry is not feasible due to production in greenhouses, production in a monocropping system and yearly replanting. For these reasons introducing of predatory mites is favourable and many generalist species are commercially available and advised for the control of thrips.

Commercially available thrips predating phytoseids are all generalist predators and are therefore able to feed on small thrips instars and pollen. Like N. cucumeris (Type III generalist predator, subtype e), Amblyseius montdorensis, Amblyseius andersoni, Amblydromalus limonicus, Amblyseius swirskii and Amblyseius degenerans are also classified by McMurtry as Type III lifestyle. However, while the former four species are typified as Subtype b: Generalist predators living on glabrous leaves, the latter is typified as Subtype c: Generalist predators living in confined space on dicotyledonous plants. The genera Euseius is classified as Type IV lifestyle: Pollen feeding generalist predators (McMurtry et al., 2013).

All these phytoseids have similar lifestyles but they vary strongly in geographic origin. A. swirskii,(holotype: Israel), A. degenerans (holotype: Italy) and A. limonicus (holotype: California, US) are widely occurring in Mediterranean, subtropical and tropical regions, whereas E. gallicus (holotype: France), N. cucumeris (holotype: France) and A. andersoni (holotype: Canada) occur in temperate and Mediterranean regions, A. montdorensis (holotype: New Caledonia) only occurs on islands of the tropical Pacific Ocean (Demite et al., 2016).

Currently these commercial predatory mites are advised and chosen based on their geographic origin and the few known temperature dependent life history parameters. Climatic conditions of strawberry production vary greatly, driven by the constant aim of producing when supply is low and therefore prices are high. The present study attempts matching the 
commercial thrips predating phytoseids with the highly diversified climatic conditions of different strawberry production systems. Therefore all (Belgian) production systems and time spans are categorized into three climate types (Table 1), simulated in climate chambers.

Table 1. The three simulated climate categories and the production conditions they include.

\begin{tabular}{cccccc}
\hline $\begin{array}{c}\text { Climate } \\
\text { Category }\end{array}$ & $\begin{array}{c}\text { Temperature } \\
\text { L:D }\left({ }^{\circ} \mathbf{C}\right)\end{array}$ & $\begin{array}{c}\text { Relative Humidity } \\
\text { L:D (\%) }\end{array}$ & $\begin{array}{c}\text { Photoperiod } \\
\text { L:D }(\mathbf{h})\end{array}$ & $\begin{array}{c}\text { Production under } \\
\text { protection }\end{array}$ & $\begin{array}{c}\text { Production in open } \\
\text { field }\end{array}$ \\
\hline A & $12: 8$ & $55: 70$ & $8: 16$ & $\begin{array}{c}\text { early and late season } \\
\text { glasshouse, early season } \\
\text { plastic tunnel }\end{array}$ & November-February \\
B & $18: 10$ & $70: 80$ & $12: 12$ & $\begin{array}{c}\text { late season plastic tunnel, } \\
\text { table top production }\end{array}$ & $\begin{array}{c}\text { March-June, } \\
\text { September-October }\end{array}$ \\
& & & & summer glasshouse & July-August \\
\hline
\end{tabular}

\section{MATERIALS AND METHODS}

\section{Predatory mites and experimental arenas}

All tested species of predatory mites were obtained from commercial producers. $A$. montdorensis and A. andersoni were acquired from Syngenta Bioline (Clacton-on-Sea, UK), A. degenerans, A. swirskii, A. cucumeris and E. gallicus from Biobest (Westerlo, Belgium) and A. limonicus from Koppert (Mechelen, Belgium). At arrival, products were stored following the directions on the product labels and the predatory mites were transferred to the experimental arenas within 3 days. The experimental detached leaf arenas were modified Munger cells (Munger, 1942). A bottom plate of acrylic $(50 \times 70 \times 2 \mathrm{~mm})$ was covered with a strip of chromatography paper $(5 \times 15 \mathrm{~cm})$, an upside down strawberry leaf $(4 \mathrm{~cm})$ and a top plate of acrylic $(5 \times 7 \times 1 \mathrm{~cm})$ with a circular cut-out $(\varnothing 2,5 \mathrm{~cm})$. The hole in the top plate is closed with a piece of nylon gauze $(4 \times 4 \mathrm{~cm})$ which is both secured and sealed to by white petroleum jelly forming a reclosable seal. The rest of the pieces are held together by clamps. The Munger cells were placed on little platforms in water filled plastic dishes, so the overhanging chromatography paper is always kept water saturated. The whole was placed in a climate chamber $\left(\right.$ Fitron $\left.{ }^{\circledR}\right)$ running the different experimental climatic conditions.

\section{Experimental procedures}

The population dynamics of $A$. degenerans, A. montdorensis, A. andersoni, $A$. limonicus, A. swirskii, N. cucumeris and E. gallicus were studied in modified Munger cells under three different simulated climates (Table 1). In the arenas an upside down strawberry leaf was placed, serving as a natural egg laying substrate and satisfying the needs of presumed plant cell piercing species like E. gallicus (McMurtry et al., 2013). Since all tested species can use pollen as a food source (McMurtry et al., 2013), Typha sp. pollen was provided as a sole food source during the experiments. Typha sp. pollen was obtained as the commercial product Nutrimite from Biobest (Westerlo, Belgium). At the start of the experiment a little heap of pollen was provided in the modified Munger cells, assuring ad libitum feeding. For each tested predatory mite species 10 replicates (Munger cells) were prepared. In each Munger cell 
10 gravid females from the commercial product were placed using a small, soft brush. . Every other day each Munger cell was opened and observed by means of a dissection microscope. When counting, distinction was made between adults, eggs and immature stages. When the life cycle of a species tended to complete (in all occurring cases on day 12), all initial adults were removed from the arenas and were placed together in another Munger cell, where their survival and progeny was further followed up. This measure gave the possibility to distinguish the progeny of the initial adults and adults from the second generation.

\section{RESULTS}

When the conditions of climate category A were simulated all species populations got reduced with $50 \%$ or more in 6 days. Except for E. gallicus, all kept steadily decreasing in numbers (Fig. 1a). The mobile population of E. gallicus started growing after 18 days when the eggs started hatching (Fig. 1b). After 30 days the immature stages started to die off, and the new adult stage was only reached in 1 of the replicates. In contrast to the other species $E$. gallicus can reproduce successful under these conditions, although reaching adulthood seems a limiting step.

For climate category $\mathrm{B}, A$. limonicus could keep its numbers relatively constant. $A$. andersoni had an immediate decline with more than $60 \%$ and then also could keep a constant number. After a certain decline the population of E. gallicus started growing, since day 6 numerous eggs started to hatch. This continued till day 16 , where a mean maximum of 22,4 immature mobile mites per arena was observed ("separated" not taken into account). After this maximum, only a small percentage became adult. However, this was sufficient to keep the number of mobile mites above 10 (Fig. 2a). Other species did not have any population build-up under these conditions.

In the experiments where the conditions of climate category $\mathrm{C}$ were simulated, only $A$. swirskii and E. gallicus showed population growth (Fig. 3a). A. limonicus also increased in number of mobile mites until day 6 but then both immature stages and adults plummeted (Fig. 3b.). The eggs of $A$. swirskii quickly hatched resulting in a fast build-up of the mobile population and a high percentage turned adult. After day 30 however, the numbers started to decrease (Fig. 3 a and c). E. gallicus produced a high amount of eggs, however the number of immatures was not in proportion. The mobile population stayed relatively constant. (Fig. $3 \mathrm{a}$ and d).

$N$. cucumeris, the most used phytoseid species in thrips control, did not perform as expected in the experiments where the conditions of climate category B were simulated. To get an idea of the influence of the factors "batch", "strain" and "transport-history" on the performance of the species, an additional experiment was carried out for $N$. cucumeris. The same experiments were done with mites obtained from three producers (Fig. 4).

\section{DISCUSSION}

The goal of the present study was to investigate, for each climate category, which commercial thrips predating phytoseids can preventively, so in absence of prey with pollen as 
a sole food source, build up a population. This as a first screening preceding evaluation for efficacy of thrips control. The results would indicate in which case what species can be preventively introduced. The outcomes are conforming to the hypothesis based on the geographic origins of the species. With E. gallicus best coping with the coldest and moderate conditions of category $\mathrm{A}$ and $\mathrm{B}$ respectively, as it is the most temperate species tested. Whereas for the warmer conditions of category $\mathrm{C}$, tropical/Mediterranean species $A$. swirskii and A. limonicus also perform better. It has to be mentioned that the diversification seen in the present results is probably not only due to intrinsic properties regarding development in relation to climatic conditions. Other possible influences to be considered are mentioned below.

The influence of the factors "batch", "strain" and "transport-history" is illustrated by comparing the performance of $N$. cucumeris of different producers (Fig. 4). Although we retrieved roughly the same population dynamics trends, there was some variation depending on the commercial source of $N$. cucumeris. This variation has to be kept in mind when interpreting the present results. It was chosen to evaluate the population dynamics in absence of prey, and all tested species are supposed being able to reproduce in such situation. Although in practice it is more likely that the diet is more diversified and that occasional prey is achieved. Hence when interpreting the results, one should consider that species that are more pollen specialised have an advantage in the used experimental set-up. There the genera Euseius is classified as Type IV lifestyle: Pollen feeding generalist predators (McMurtry et al., 2013), this consideration can account to the fact that E. gallicus was amongst the best performing species in each climatic condition.

Similar experiments concerning rearing of phytoseids on pollen show a similar trend of the population staying constant instead of increasing, this most likely can be attributed to a progressive shortage by relying on the nutritive quality of the pollen and difficulty in water intake (Castagnoli et al., 1999). Water uptake by the predatory mites in the used Munger-cells possibly also can be insufficient/unrealistic. Where in nature prey haemolymph and water droplets are available as a water source, the phytoseids in this study solely depended on the humidity of the pollen. Species that are able to pierce plant cells and feed on the cell sap hence possibly have an advantage in the used experimental set-up. Plant cell feeding is known for E. gallicus (McMurtry et al., 2013), A. limonicus (McMurtry et al., 2013)(Vangansbeke et al., 2014), and A. degenerans (Adar et al., 2015). It is known that A. swirskii is not able to pierce plant cells (Adar et al., 2015) and this is also suggested for other Amblyseius species and Neoseiulus species like N. cucumeris (Adar et al., 2014).

For some tested species the strawberry leaf in the Munger-cells is not the preferred habitat, these species can be excluded for bio-control in strawberry, however it is possible that in other crops they perform better under the same climatic conditions. An example would be A. degenerans, a species strongly associated with domatia which are absent in strawberry plants (McMurtry et al., 2013). 
Due to the limited space in the Munger-cells the possibility exists that at high population densities adverse effects like competition, cannibalism and escaping behaviour appear and result in an underestimation of the potential population growth.

It is known that diurnal alternating temperatures influence the development of predatory mites (Vangansbeke et al., 2015). It is hence probable that alternations within time spans less than 24 hours also can result in faster or slower development than the mean constant temperature. In glasshouses temperatures can be kept constant, whereas in more open systems temperature can strongly vary. As a result, the used simulated conditions can give slightly different results for open systems.

\section{CONCLUSIONS}

Under the coldest condition (A), the in West-Europe indigenous E. gallicus was the only species with a significant population build up. When moderate conditions (B) were simulated E. gallicus, N. cucumeris and A. limonicus were most successful. The warmest regime (C) was most adequate for E. gallicus and $A$. swirskii.

\section{ACKNOWLEDGEMENTS}

This research was funded by project number 120746 from the Institute for the Promotion of Innovation through Science and Technology in Flanders (IWT-Vlaanderen)

\section{Literature cited}

Adar, E., Inbar, M., Gal, S., and Palevsky, E. (2014). Utilising Plant Feeding Phytoseiid Predators for Pest Control : Pros and Cons. Acta Hortic. 1041, 141-148.

Adar, E., Inbar, M., Gal, S., Issman, L., and Palevsky, E. (2015). Plant cell piercing by a predatory mite: evidence and implications. Exp. Appl. Acarol. 65, 181-193.

Van Baal, E., Van Houten, Y., Hoogerbrugge, H., and Bolckmans, K.J.F. (2007). Side effect on thrips of the spider mite predator Neoseiulus californicus. Biol. Control 18, 37-42.

Castagnoli, M., Simoni, S., and Biliotti, N. (1999). Mass-rearing of Amblyseius californicus (Acari: Phytoseiidae) on two alternative food sources. In Ecology and Evolution of the Acari, J. Bruin, L.P.S. van der Geest, and M.W. Sabelis, eds. (Dordrecht: Kluwer Academic Puhlishers), pp. 425-431.

Demite, P.R., Moraes, G.J. de, McMurtry, J.A., Denmark, H.A., and Castilho, R.C. (2016). Phytoseiidae Database. Available from: www.lea.esalq.usp.br/phytoseiidae (accessed 11/05/2016).

Fitzgerald, J., Pepper, N., Easterbrook, M., Pope, T., and Solomon, M. (2007). Interactions among phytophagous mites, and introduced and naturally occurring predatory mites, on strawberry in the UK. Exp. Appl. Acarol. 43, 33-47. 
McMurtry, J. a., De Moraes, G.J., and Sourassou, N.F. (2013). Revision of the life styles of phytoseiid mites (Acari: Phytoseiidae) and implications for biological control strategies. Syst. Appl. Acarol. 18, 297-320.

Munger, F. (1942). A Method for Rearing Citrus Thrips in the Laboratory. J. Econ. Entomol. $35,373-375$.

Vangansbeke, D., Nguyen, D.T., Audenaert, J., Verhoeven, R., Gobin, B., Tirry, L., and de Clercq, P. (2014). Performance of the predatory mite Amblydromalus limonicus on factitious foods. BioControl 59, 67-77.

Vangansbeke, D., Audenaert, J., Nguyen, D.T., Verhoeven, R., Gobin, B., Tirry, L., and De Clercq, P. (2015). Diurnal temperature variations affect development of a herbivorous arthropod pest and its predators. PLoS One 10,1-19.

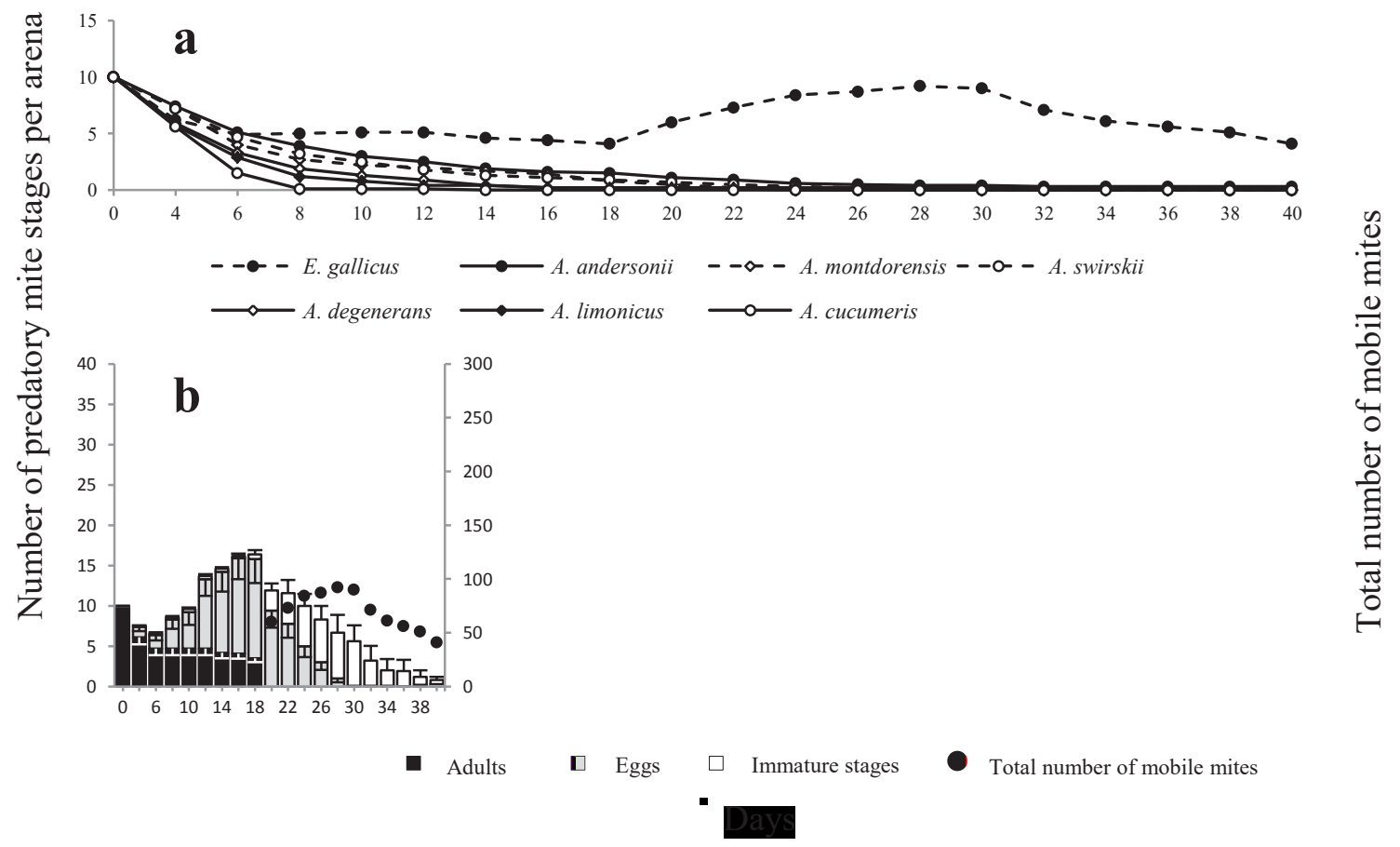

Figure 1: Climate category A. a. Population dynamics as the total number of mobile mites per arena. b. Population dynamics of E. gallicus. The initial adults were removed from the arenas when a life cycle tended to complete (day 18), dots represent the total number of mobile mites over all arenas, the separated initial adults and their progeny after separation included. Error bars represent $+\mathrm{SE}$ or $-\mathrm{SE}$. 


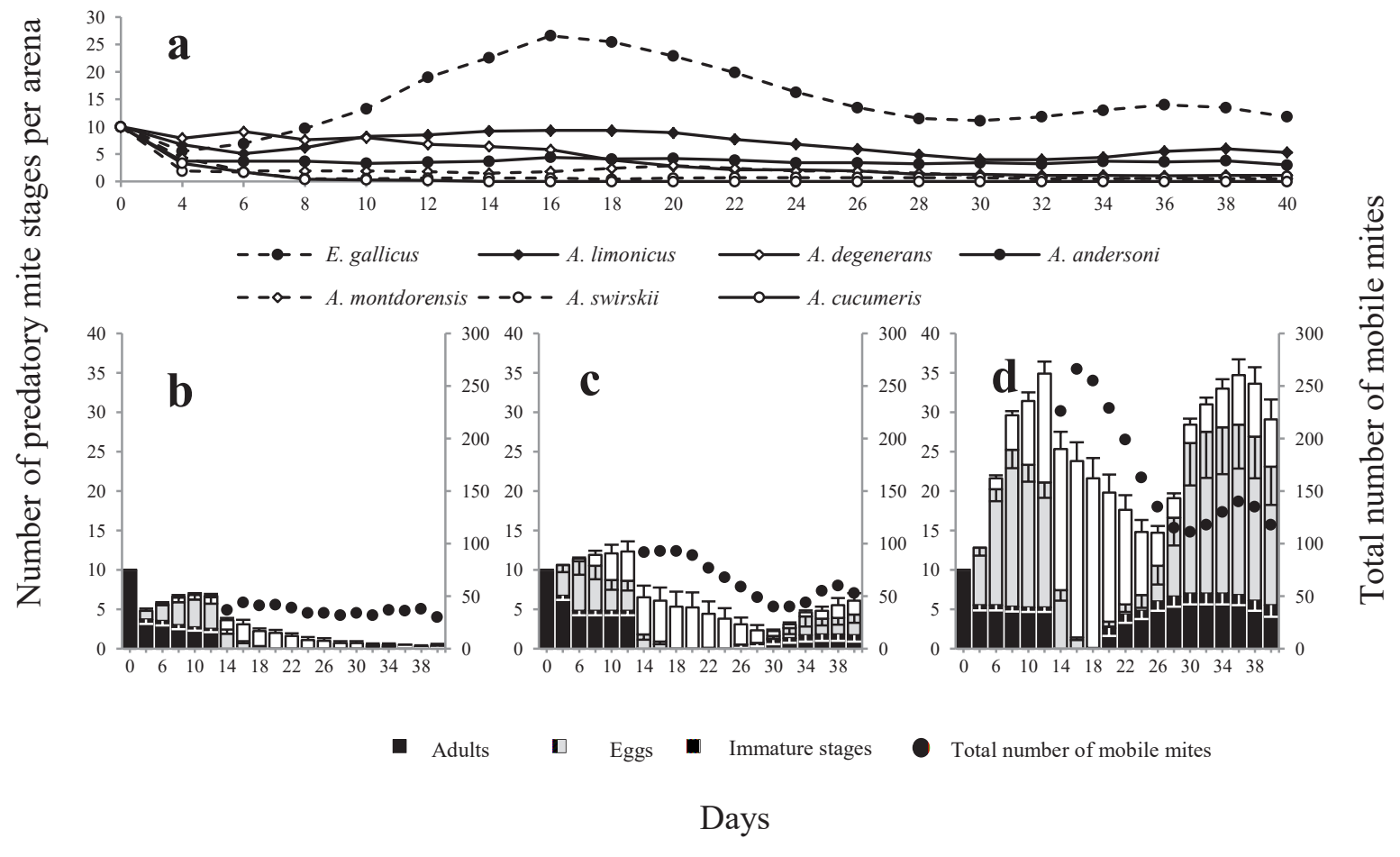

Figure 2: Climate category B. a. Population dynamics as the total number of mobile mites per arena. b. Population dynamics of $A$. andersoni. c. Population dynamics of A. limonicus. d. Population dynamics of E. gallicus. The initial adults were removed from the arenas when a life cycle tended to complete (day 12), dots represent the total number of mobile mites over all arenas, the separated initial adults and their progeny after separation included. Error bars represent $+\mathrm{SE}$ or $-\mathrm{SE}$.

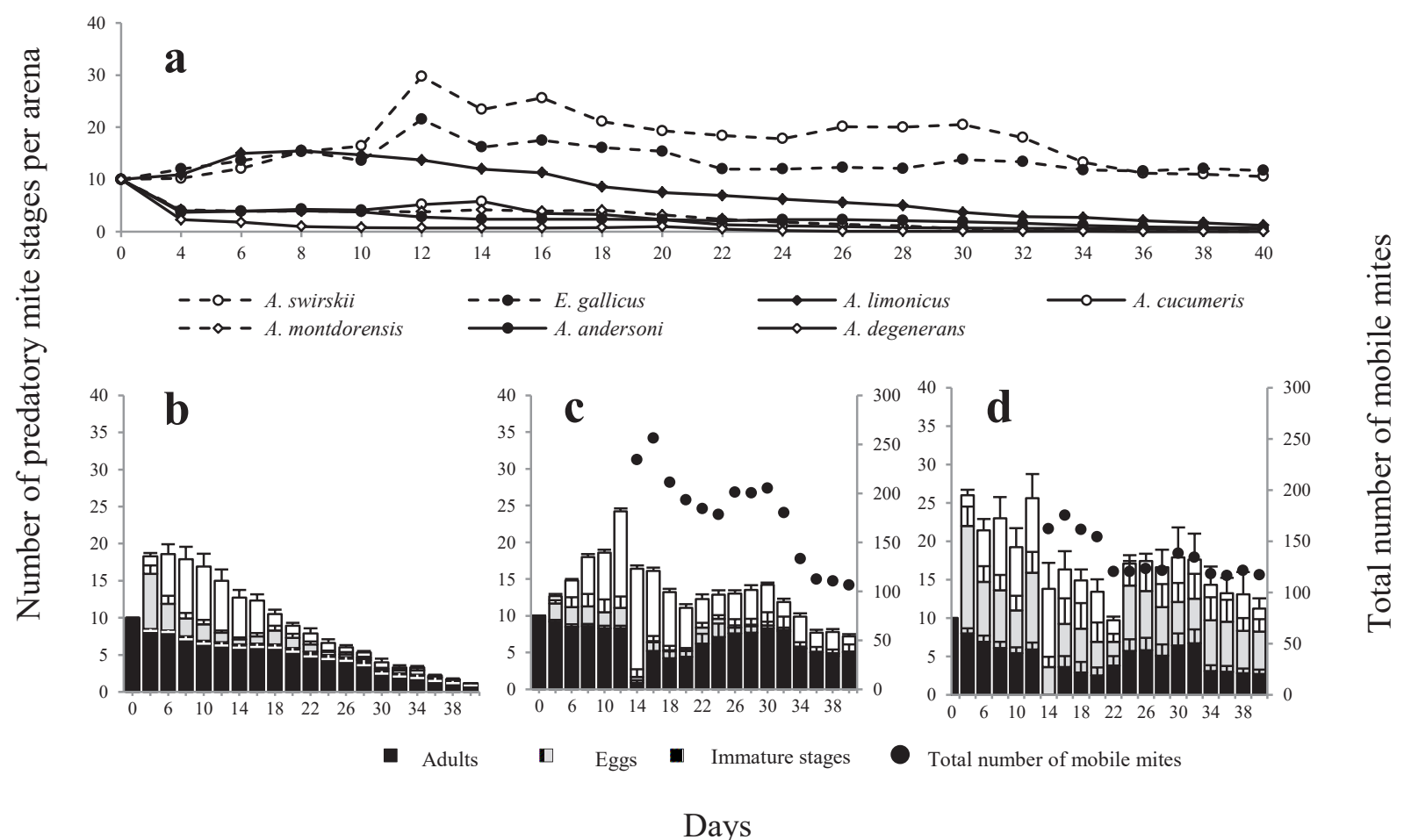

Figure 3: Climate category C. a. Population dynamics as the total number of mobile mites per arena. b. Population dynamics of A. limonicus. c. Population dynamics of A. swirskii. d. Population dynamics of E. gallicus. The initial adults were removed from the arenas when a life cycle tended to complete (day 12), dots represent the total number of mobile mites over all arenas, the separated initial adults and their progeny after separation included. Error bars represent $+\mathrm{SE}$ or $-\mathrm{SE}$. 


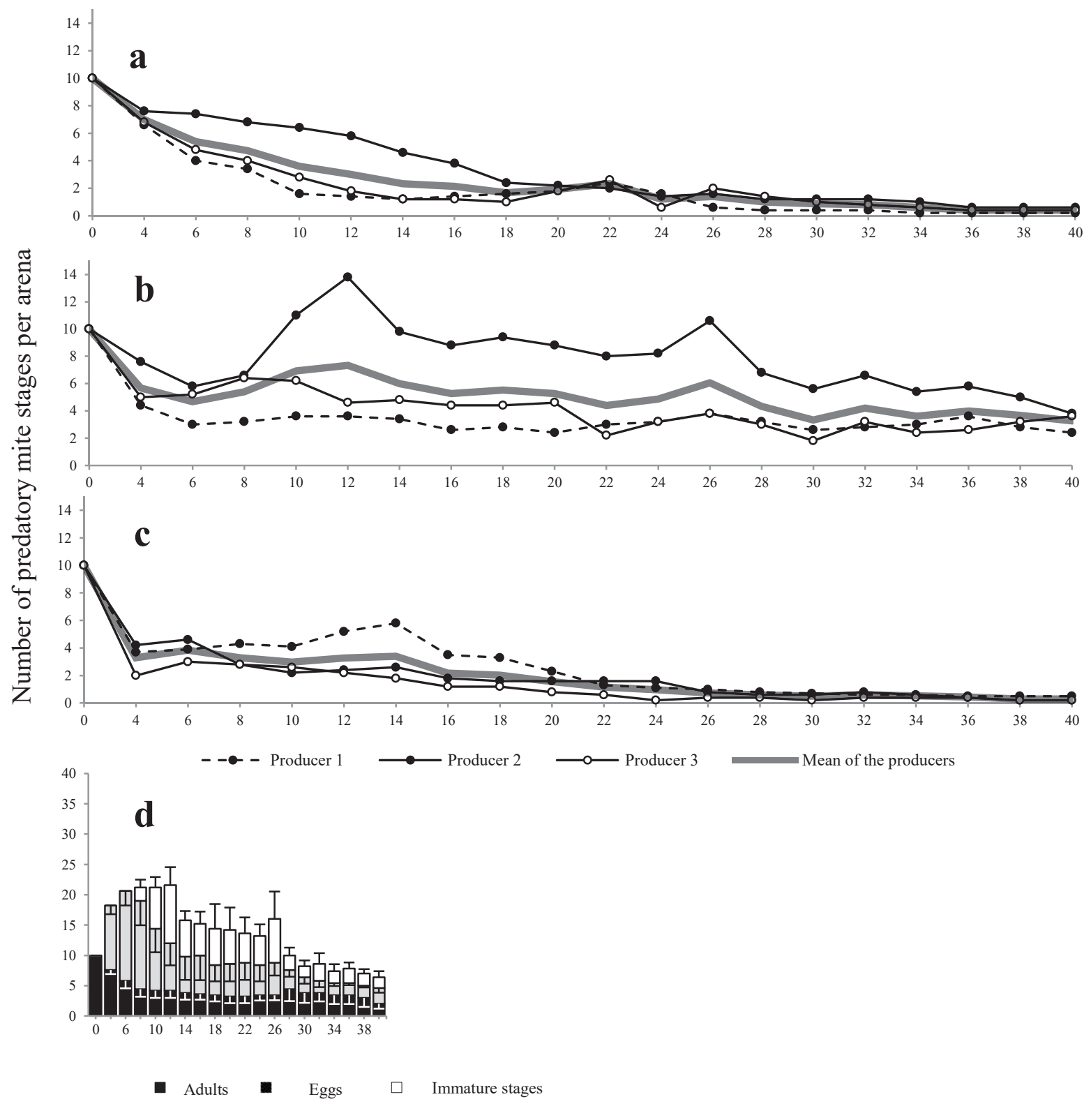

Days

Figure 4: a. Population dynamics as mobile stages of N. cucumeris for climate category A. b. Population dynamics as mobile stages of $N$. cucumeris for climate category B. c. Population dynamics as mobile stages of $N$. cucumeris for climate category C. d. Population dynamics of $N$. cucumeris for climate category B, Producer 2. Error bars represent $+\mathrm{SE}$ or $-\mathrm{SE}$. 